\title{
Discurso para la apertura del Programa de Terapia Ocupacional en la Escuela Nacional del Deporte, Cali, 27 de abril de $2015^{1}$
}

\author{
Solángel García Ruiz²
}

Buenas tardes a todas y todos.

Es para mi un honor participar en esta reunión de apertura del programa número doce de Terapia Ocupacional en Colombia y el cuarto de una universidad pública.

Cuando empecé a escribir estas palabras no sabía por dónde empezar, hablé con colegas, conversé con mi familia, pregunté a otros tratando de identificar qué sería lo fundamental que yo pudiese transmitir en este espacio hoy. Vivía también un momento de consternación al ver una y otra vez las noticias de Katmandú, en Nepal, y pensaba en los templos y los dioses, en las personas, quienes hace dos años contribuyeron con mi inspiración en una caminata larga por ese lugar, acompañada por el silencio de los lugares, por la belleza de los templos, por la sensación que allí respiraba, por la tranquilidad que sintió mi mente y mi espíritu al disfrutar ese lugar; hoy, al escribir esto, pensaba en la gente y en sus espacios, y quería que mi mente mantuviera presentes los lugares que un día conocí, los rostros que un día vi, los ojos que se cruzaron con los míos y que quizás hoy no existan. Así que decidí implorar a los dioses de ese lugar para hablar de la Terapia Ocupacional en este lugar.

En Colombia, este país de grandes montañas y ríos, de riquezas inigualables, las del petróleo, el carbón, el café; de inequidades infinitas, de dolores intensos y de felicidades diversas. Ahora, cuando en el país se habla del post conflicto, quizás mejor, del post acuerdo, cuando finalmente decidimos comenzar a hablar de la memoria para reconstruir la guerra desde las palabras y los dolores, desde las rabias y los miedos, desde los amores y desamores; en tiempos en los que finalmente nos invitan a poner palabras a las sensaciones que hemos vivido en todos estos años, tiempos en

\footnotetext{
${ }^{1}$ En 2015 se produjo un hecho significativo para la historia de la Terapia Ocupacional colombiana, la apertura de un nuevo programa de formación profesional, esta vez en la Escuela Nacional del Deporte, una institución universitaria pública con sede en la ciudad de Cali. La terapeuta ocupacional Solángel García Ruiz fue invitada por las directivas de la Escuela y del nuevo programa a la ceremonia de apertura del mismo, que se llevó a cabo el 27 de abril de 2015. La Revista Ocupación Humana agradece a ella, a la coordinadora del programa, terapeuta ocupacional Diana Ximena Martínez, y a las directivas de la Escuela, por su generosidad al compartir este texto con la comunidad de Terapia Ocupacional del país.

2 Terapeuta ocupacional. Magister en desarrollo social y educativo. Coordinadora de investigaciones, Secretaría Distrital de Salud de Bogotá. Miembro de la Red Mundial de Rehabilitación Basada en la Comunidad. Bogotá, Colombia.
} 
los que debemos empezar a trabajar en la confianza, en esa que construye redes, en esa que hace amigos, en esa que se trabaja el perdón, esa que será seguro muy difícil y que seguro, para construirla, tendremos que caminar sobre las utopías, las esperanzas y los sueños.

En estos tiempos en los que comenzamos la reconstrucción de aproximadamente cinco décadas de la práctica de la Terapia Ocupacional en Colombia, cuando en nuestros discursos se han cruzado términos y palabras como la ocupación humana, el desempeño ocupacional, el comportamiento ocupacional, la ciencia ocupacional, el apartheid ocupacional, la justicia ocupacional, cuando la práctica de la Terapia Ocupacional ha caminado más allá de la teoría, ha vivido entre luchas, cuando las condiciones de vida de las personas, los acontecimientos naturales y humanos nos han exigido a los terapeutas ocupacionales ocuparnos de asuntos distintos a los tradicionales.

Lo tradicional para la Terapia Ocupacional ha sido la atención hacia la discapacidad, en comienzos desde una perspectiva de la rehabilitación, luego desde una propuesta de integración y ahora desde una mirada de la inclusión y los derechos humanos, pero, este tránsito va mas allá; la comprensión de la ocupación va más allá de cualquiera de sus adjetivos, comprender la ocupación tiene que ver con algo más sencillo, y es con ser felices con lo que cada uno hace, es con que nosotros seamos felices con lo que hacemos, tiene que ver con encontrar la pasión, la que sale de la panza, la que brilla con los ojos, la que sonríe con la vida y esa tiene que ver con todas las personas, con todos nosotros y con los otros...

Ahora cuando ustedes proponen un programa de Terapia Ocupacional en una escuela del deporte, en los tiempos que emergen en Colombia grandes deportistas que son nuestro orgullo, en tiempos donde el deporte puede jugar un papel importante en el postconflicto, ahí cuando el deporte y su práctica se identifican como derechos, como ocupaciones. En ese lugar, desde el deporte, donde se mira la salud desde la salud, la capacidad y la vida; siendo, a mi modo de ver, uno de los principales asuntos que se debe promover desde las políticas de salud, si en realidad se quieren cambiar sus indicadores.

Y esto, que parece una utopía en estos tiempos, cuando se habla de una Terapia Ocupacional desde las ciencias de la salud (tradicionalmente vista) o desde las ciencias sociales y políticas, cuando el país quiere medir el conocimiento con indicadores de cienciometría y no por las transformaciones sociales, políticas y económicas que logremos con los aprendizajes; cuando la práctica se mide con registros, informes, fotos, actas, que no son para construir la memoria ni para hacer proceso, sino para tener la evidencia de lo que se hace. Sí, en estos tiempos, cuando caminamos en la modernidad y con deseos de liberarnos de las ataduras de su estandarización y su homogenización hacia algo más contemporáneo e invitarnos a comprender la realidad desde posturas de pensamiento complejo, donde no solo se vea lo que pasa, sino sus significados, 
donde los asuntos vayan más allá de ver lo lineal, sino más bien de reconocer todos los entramados.

En estos tiempos es cuando pensamos cuáles son los terapeutas ocupacionales que se requieren mañana para contribuir en la transformación de la vida de este país y por qué no, en la de los países vecinos.

Entonces, es cuando pienso que se requieren terapeutas soñadores, visionarios, con capacidad de ver la profundidad de la vida en la vida, donde las utopías (como las que hablaba Galeano) sean parte de su inspiración.

Se requieren terapeutas que se reconozcan como ciudadanos y que reconozcan a todos los sujetos con los que se encuentran en su práctica de la misma manera. Ciudadanos empoderados y emancipados, con la posibilidad de tomar claras decisiones sobre su vida y sus lugares, con capacidades de contribuir en la consolidación de lugares y culturas en paz y para la paz.

Terapeutas promotores de la democracia y la participación, con capacidad de comprender y promover los rasgos históricos de la democracia dados por el pluralismo o la capacidad de defender las diversidades y el disenso; la competencia o la posibilidad de ver los distintos intereses e ideologías políticas que pueden acceder al poder del Estado, las elecciones, el principio de mayoría y el constitucionalismo como respeto por los derechos civiles y políticos.

Terapeutas que vivan el mundo glocal, como diría Boaventura de Sousa, ese que les permite actuar en lo local y pensar en lo global, con la posibilidad de entender y comprender el significado del mundo, de las relaciones políticas, económicas y sociales del mundo global y actuar localmente en concordancia con las necesidades locales, las de los territorios donde la gente vive, llora y ríe.

Terapeutas con claros valores éticos, capacidades de contribuir para que en la sociedad colombiana superemos la crisis de valores y superar las décadas de validar la guerra, el narcotráfico, la impunidad, entre otros; a caminos donde la dignidad, el respeto, el reconocimiento, la transparencia, se vayan haciendo naturales; seguro que serán varias generaciones de colombianos las que requeriremos para transitar a estos caminos.

Terapeutas capaces de armar redes, como diría Patricia Quintana, de armar las redes de los afectos y a partir de allí, las redes, las conexiones locales, nacionales e internacionales, aquellas que nos permiten aprender y comprender de otros y con otros sobre los asuntos que se suceden al tiempo en otros lugares del mundo y en nuestro mundo también.

Terapeutas con el sentido del reconocimiento cultural, de las costumbres, de las más de 65 lenguas que se hablan en este país; con la posibilidad de ver, comprender y contribuir con la emancipación de los ciudadanos, y no mirados exactamente por una condición, llámese discapacidad, indígena, desplazado, desmovilizado o demás, sino exactamente por su dignidad y su esencia como ser humano. 
Terapeutas capaces de contribuir con el medio ambiente, con el cuidado de la vida, no solo la humana, para nosotros y para las generaciones venideras.

Terapeutas que actuarán como asesores y consultores de la vida de los sujetos, de las familias, de los gobiernos grandes y pequeños, de las localidades, las comunas, los corregimientos, pero también de las ciudades y los gobiernos. Allí, para contribuir con la justicia ocupacional, con la eliminación del apartheid ocupacional, con la construcción de las democracias.

Terapeutas donde los conocimientos desde la biología, la biomecánica, se mezclen con los de las políticas, se reflexionen desde la ética, se comprendan desde las humanidades, se aclaren desde las tecnologías y se proyecten desde la ocupación en cualquiera de los lugares y cualquiera de sus modelos o teorías.

Es decir, terapeutas que actuarán como ciudadanos y apoyarán a otros ciudadanos en su trasegar por la vida.

Así que bienvenidos a la construcción de país desde la Terapia Ocupacional en Colombia.

Muchas gracias. 